\title{
THE VALUE OF THE DISTANT FUTURE: THE PROCESS OF DISCOUNT IN RANDOM
} ENVIRONMENTS

\author{
JAUME MASOLIVER \\ Department of Condensed Matter Physics and Institute of Complex Systems (UBICS). UNIVERSIDAD DE \\ BARCELONA, ESPAÑA \\ E-mail: jaume.masoliver@ub.edu
}

\begin{abstract}
We analyze how future costs must be balanced against present costs. This is traditionally done using an exponential function with a constant discount rate. The choice of discount rate can dramatically e_ect the question on what is the value of the future. This is specially critical for environmental problems such as global warming, and it has generated a controversy as to the urgency for immediate action (Stern, 2006; Nordhaus, 2007a,b). We briey review the issue for the nonspecialist and take into account the randomness of the economic evolution by studying the discount function of three widely used processes for the dynamics of interest rates: Ornstein-Uhlenbeck, Feller and log-normal.We also outline our previous empirical survey on 9 stable countries (countries that have not su_ered periods of destabilizing ination) over time spans ranging up to more than 300 years (Farmer et. al. 2014). We estimate the parameters of one of the models studied (the Ornstein-Uhlenbeck process) and obtain the long-run discount rate for all these countries. The long-run discount obtained supports the low discounting rate proposed by Stern (2006) over higher rates that have been advocated by others (Nordhaus, 2007a,b).
\end{abstract}

Key words: Discounting. Environment. Interest rates. Inflation. Market price of risk. Ornstein-Uhlenbeck procesess

\section{EI valor del futuro distante: EI proceso de descuento en entornos aleatorios}

\section{RESUMEN}

Se analizan como deben comparase los costos futuros con los costos presentes. Generalmente este proceso se realiza mediante una función exponencial con una tasa constante de descuento. La elección de dicha tasa afecta de forma crítica cual es el valor del futuro. Ello es estratégico para los problemas medioambientales como el calentamiento global y ha generado una gran controversia sobre la urgencia en tomar las medidas adecuadas de forma inmediata (Stern, 2006; Nordhaus, 2007 a,b). Revisamos de forma breve el problema para el no especialista y tenemos en cuenta la aleatoriedad en la evolución económica mediante el estudio de tres modelos ampliamente usados para la evolución dinámica de los tipos de interés: Los procesos de Ornstein-Uhlenbeck, Feller y el log-normal. También resumimos un estudio empírico que hemos realizado sobre 9 países estables durante periodos de tiempo que pueden llegar a los 300 años (Farmer et. al. 2014). Usando el modelo de OrnsteinUhlenbeck estimamos de los datos empíricos los parámetros del modelo lo que nos permite obtener las tasa de descuento a largo plazo de estos países estables. Las tasas de descuento así obtenidas avalan la baja tasa de descuento propuesta por Stern (2006) en lugar de la más elevada propuesta por otros investigadores (Nordhauss, $2007 \mathrm{a}, \mathrm{b}$ )

Palabras clave: Descuento. Medio ambiente. Tasas de interés. Inflación. Precio de mercado del riesgo. Proceso Ornstein-Uhlenbeck

Clasificación JEL: C1, G12, Q5 


\section{INTRODUCCIÓN}

One important quantitative procedure in economics and finance is that of "discounting". This process tries to answer a key question: How can we value the future? The discounting mechanism weights the future relative to the present and the weighting method is carried through a discount function which usually takes the form of a decreasing exponential (Samuelson, 1937). Indeed, under a steady rate of interest $r$, a dollar inverted today, at time $t=0$, will yield $e^{r t}$ at time $t>0$. That is to say, a dollar in any future time $t$ is worth $e^{-r t}$ today.

In this simple example $r$ is fixed but in practice rates are uncertain and it is not realistic to represent discounting by a deterministic function of time such as the decreasing exponential with a fixed rate and some kind of average over all possible interest rate paths must be taken. Before developing these ideas, let us remark that the problem of discounting shows its great importance not only in finance but in longrun environmental planning (Dasgupta, 2004). Indeed, and assuming again a steady rate of interest, an environmental problem that costs $X$ to fix at time $t$ in the future is equivalent to an investment of $e^{-r t} X$ today. Thus if $r$ is substantial, any benefit at some distant time would justify a negligible investment now. Therefore, high long-run interest rates favor nonintervention while lower rates advocate for more immediate measures. Letting interest rates to be a proxy for economic growth, a different version of the above argument is that technologies in the future will be so powerful that they will overshadow anything we can achieve with present day technology. In this sense it is more rational to follow policies fostering economic growth than try to combat global warning now.

Remaining within long-run discounting, it is no surprise that the choice of a discount rate has vast consequences and is the object of intense debates and contradictory estimates (Arrow et al., 2013). For example, in a highly influential report on climate change commissioned by the UK government, Stern (2006) uses a discount rate of $1.4 \%$, which on a 100-year horizon implies a present value of $25 \%$ (meaning the future is worth $25 \%$ as much as the present). In contrast, Nordhaus (2007b) argues for a discount rate of $4 \%$, which implies a present value of $2 \%$, and at other times has advocated rates as high as $6 \%$ (Nordhaus, 2007a), which implies a present value of $0.3 \%$. Stern has been widely criticized for using such a low rate (Nordhaus, 2007b, a; Dasgupta, 2006; Mendelsohn, 2006; Weitzman, 2007; Nordhaus, 2008). The choice of discount rate is probably the biggest factor influencing the debate on the urgency to respond to global warning and the issue is far from being settled. What is the right number? And is it even correct to use an exponential discount?

For environmental problems normative approaches to choosing discount rates are based on ethical grounds and assumptions about economic growth (Stern, 2014a, b). They also depend on arguments involving the maximization of utility functions that are chosen for mathematical convenience (Heal and Milner, 2014). Economists present a variety of reasons for discounting, including impatience, economic growth and declining marginal utility; all of them embedded in the Ramsey formula (Ramsey, 1928), which forms the basis for standard approaches to discounting (Arrow et al., 2013).

However, as mentioned above, rates are uncertain and it is not realistic to represent discounting by deterministic functions of time such as decreasing exponentials with a fixed rate and, therefore, some kind of average over all interest rate paths must be taken. This problem is particularly severe for environmental problems, where in questions such as global warming one must consider costs and benefits 100 or more years in the future. It also occurs in finance, where discounting times are typically thirty years or less, where it has long been recognized that interest rates must be modeled as random processes (Vasicek, 1977; Cox, Ingersoll, and Ross, 1985; Dothan, 1978; Brigo and Mercurio, 2006).

A more positive approach to discounting consists in figuring out how the market trades off present consumption for future consumption. For the near future one can readily find the corresponding market interest rate for money, and by making assumptions about likely inflation one can infer the market discount rate for real consumption (see, for instance, Newell and Pizer 2003, or Farmer et al. 2014). For the distant future, a practical economist engaged in the environmental debate might try to use, as the forward discount rate, the average of historical interest rates which occurred in the last 200 hundred years (2.7\% in stable countries (Farmer et al., 2014)), or take the average of Wall Street forward looking models which price bonds of maturity as long as 30 years. However, we have shown (Farmer et al., 2014) that, due to historical fluctuations of short real interest rates, the appropriate rate is considerably below these averages. 
Moreover, the presence of fluctuations can dramatically alter the functional form of the discount function. If interest rates follow a geometric random walk, for example, Farmer and Geanakoplos (2009) (see also Geanakoplos et al., 2014) have shown that in some circumstances the discount function decays as a power law of the form $t^{-1 / 2}$. They called this hyperbolic discount because the discount factor obeys the equation of a hyperbola instead of the usual exponential function. In the large time limit a hyperbolic function is much greater than any exponentially decaying function, showing that there is no positive long run rate of interest in this case. The hyperbola assigns an infinite value to any permanent positive flow of consumption, meaning that the infinite future is infinitely valuable.

Nonetheless, anecdotal evidence suggests that long-term exponential behavior is the typical case. We have examined a variety of different processes, including more general log-normal processes, the Feller process, and the Ornstein-Uhlenbeck process (Farmer et al. 2015). We have found that the case of the simple log-normal process studied by Farmer and Geanakoplos (2009) was the only one that did not display long-term exponential behavior. All the other examples deviated from exponential behavior for short times, but, for a wide range of parameters, eventually converged to an exponential function. This suggests that, while the transient non-exponential behavior can be important for a few decades, the most important question is the long-term discount rate.

Which model is most appropriate depends on the problem under study. Thus if we deal with environmental problems we should use real rates which are nominal interest rates corrected by inflation. In Sect. IV we present the main results of an empirical study that we have recently done on real rates of 9 stable countries which have not suffered periods of destabilizing inflation. The survey covers 87 to 318 years (see Farmer et al., 2014, and Sect. IV for details). Data clearly show that in many epochs and for all countries real rates frequently become negative, often by substantial amounts and for long periods of time. In environmental problems we are, therefore, lead to the Ornstein-Uhlenbeck process, since that model allows for negative values, while other processes, such as Feller or log-normal, exclusively deal with positive values. However, financial settings use nominal rates which usually are positive and, therefore, either the Feller or the log-normal processes are more appropriate (Brigo and Mercurio, 2006). In Sect. III we will present a summary on the key results of each model.

Let us finally stress three important facts. Firstly, assuming that costs and benefits can be reduced to monetary values, the discounting problem is equivalent to bond pricing. A bond is an instrument that one can purchase now that delivers a payment in the future. Similarly, to combat climate change we must spend now in order to receive environmental and economic benefits in the future. If we can quantify both the expenditure required now and the likely cost of inaction in the future, then the price of the corresponding bond gives us an indication of the discount factor. We must say, nonetheless, that there are always intangible effects that are difficult to quantify in monetary terms, and one should be suspicious of any procedure that reduces the existence of a species or a human life to a dollar value. But it is nonetheless informative to see what a purely monetary analysis implies.

Secondly, the interest rate for bonds as a function of their time to maturity is called the yield curve. Most bonds have a time to maturity of 30 years or less, but for environmental problems such as climate change we need to know the discount 100 years or more into the future. We do not have data on bonds of such long maturity. Thus we are faced with the problem of inferring the price of long maturity bonds from data on much shorter maturity bonds. Furthermore, the yield curve fluctuates substantially from year to year, so we need sufficient historical time series for reliable statistical inference. In order to do this we need a reasonable model for real interest rates at different maturities.

Thirdly, in addition to the factors that determine the overall level of short term rates, there is one effect influencing long term rates that must be taken into account. This is the so-called "risk aversion". All of this implies the modification of the probability distribution obtained from the empirical data as we will explain in later sections. The far future is less certain than the near future, so all else equal, we expect that longer term bonds bear greater risk, which should imply higher interest rates.

In the rest of this paper we will develop and summarize all these ideas concerning discounting into a consistent framework which I will try to expose in a clear and intuitive way. 


\section{THE PROCESS OF DISCOUNTING IN CONTINUOUS TIME}

In economics the increment at a given time of the quantity of wealth, exemplified by some magnitude $M=M(t)$, is assumed to depend linearly on the quantity itself and the duration of the variation. For a continuous and instantaneous variation one the writes:

$$
d M(t) \propto M(t) d t
$$

This is a phenomenological law base on the empirical fact that the bigger $M(t)$, the greater its variation at a given time, but also on the simplifying assumption that the increment is linear in $M(t)$ and not, for instance, quadratic. Let us incidentally note that linearity is equivalent to assuming that the interest rate, defined as the relative time derivative

$$
r=\frac{1}{M(t)} \frac{d M(t)}{d t}
$$

is independent of $M(t)$. Note that this definition can be written as

$$
r=\frac{d \ln M}{d t}
$$

so that the rate is the derivative of the logarithm of wealth.

In the simplest situation the growth law (1) represents a completely linear law with direct proportionality in which $r$ is constant:

$$
d M(t)=r M(t) d t
$$

where $r$ is the rate and is measured in units of 1/(time). Now the growth law is readily integrated, giving

$$
M(t)=e^{r\left(t-t_{0}\right)} M\left(t_{0}\right)
$$

which yields an exponential growth connecting wealth at time $t$ with that of some earlier time $t_{0}<t$.

Before proceeding further, we recall that the growth law (1), often in the simplest version (4), appears in numerous branches of physical and social sciences. Thus, for example, in radioactivity if $N(t)$ is the number of active nuclei at time $t$, the usual hypothesis is that this number decrease as

$$
d N(t)=-\lambda N(t) d t,
$$

where $\lambda>0$ is the decay constant. Similar considerations apply to other situations, as they are for instance found in chemical reactions and population dynamics, as well as in many other situations.

In economics, discounting refers to the process of connecting wealth at different times. Specifically the discount function, which we denote by $\delta(t)$, is defined by

$$
\delta(t) \equiv \frac{M\left(t_{0}\right)}{M(t)}
$$

so that $M\left(t_{0}\right)=\delta(t) M(t)$ in accordance with the fact that discounting specifically refers to weighting the future at some time $t$ relative to $t_{0}\left(t>t_{0}\right)$.

In the simplest case of Eq. (5) the discount function is given by the decreasing exponential:

$$
\delta(t)=e^{-r\left(t-t_{0}\right)}
$$

where $r>0$ is the interest rate. However, as we have mentioned above, this simple form of discount, in which the interest rate is always constant, is unrealistic. A first generalization consists in assuming rates to be deterministic functions of time $r(t)$. In such a case the growth law (4) is generalized to

$$
d M(t)=r(t) M(t) d t
$$

which after integrating yields

$$
M(t)=M\left(t_{0}\right) \exp \left(\int_{t_{0}}^{t} r\left(t^{\prime}\right) d t^{\prime}\right)
$$


and discount is now given by

$$
\delta(t)=\exp \left(-\int_{t_{0}}^{t} r\left(t^{\prime}\right) d t^{\prime}\right)
$$

Obviously if $r(t)=r$ is constant we recover the simple exponential decay of Eq. (7).

However, the assumption of rates being given by constants or by deterministic functions of time is unreasonable, at least over long periods of time. Financial interest rates are typically described as random, as the many models for stochastic interest rates appearing in the literature show (Brigo and Mercurio, 2006). Population dynamics are subject to random influences, as are chemical reactions and other physical processes where rates appear.

We therefore assume that $r(t)$ is a random function of time. This naturally means that discounting $\delta(t)$ is also random, as is clearly seen in Eq. (9). In these circumstances the effective discount function is defined as the average of $\delta(t)$ :

$$
D(t)=\mathbb{E}\left[\exp \left(-\int_{t_{0}}^{t} r\left(t^{\prime}\right) d t^{\prime}\right)\right]
$$

where the expectation $\mathbb{E}[$.$] represents the average over all real trajectories of r(t)$ up to time $t$ and $t_{0}$ is an arbitrary initial time. ${ }^{23}$

Let us incidentally note that the problem of discounting -as expressed by Eqs. (9) and (10)- is formally identical to the problem of pricing bonds. Indeed, the price $B\left(t_{0} \mid t+t_{0}\right)$ of a zero-coupon bond issued at time $t_{0}$ which unit payoff and maturing at time $t+t_{0}(t \geq 0)$ is (Brigo and Mercurio, 2006, see also Appendix B).

$$
B\left(t_{0} \mid t+t_{0}\right)=\exp \left(-\int_{t_{0}}^{t} n\left(t_{0}, t^{\prime}\right) d t^{\prime}\right)
$$

where $n\left(t_{0}, t\right)$ is the nominal rate. The differences between these two problens is that for discounting we are interested in real interest rates $r(t)$-which can be negative due to inflation- whereas for bond pricing we are typically interested in the nominal rate $n\left(t_{0}, t\right)$.

The real interest rate $r(t)$ can, in principle, be any random process. However, the simplest and most common hypothesis consists in assuming that is that rates are described by a Markovian process with continuous sample paths. That is, we assume that $r(t)$ is a diffusion process whose time evolution is governed by a stochastic differential equation of the form.

$$
d r=f(r) d t+g(r) d W(t)
$$

where $f(r)$ is the drift, $g(r)>0$ is the noise intensity and $W(t)$ is the standard Wiener process.

Looking at Eq. (10) we see that, in terms of the cumulative process

$$
x(t) \int_{t_{0}}^{t} r\left(t^{\prime}\right) d t^{\prime}
$$

the discount function can be written as

$$
D(t)=\mathbb{E}\left[e^{-x(t)}\right]
$$

which shows that, in terms of the probability density function (PDF) $p\left(x, r, t \mid x_{0}, r_{0}, t_{0}\right)$ of the bidimensional diffusion process $(x(t), r(t)),{ }^{24}$ the effective discount can be written as

$$
D(t)=\int_{-\infty}^{\infty} d r \int_{-\infty}^{\infty} e^{-x} p\left(x, r, t \mid x_{0}, r_{0}, t_{0}\right) d x
$$

\footnotetext{
${ }^{23}$ Usually $t_{0}$ refers to the present time, which in our case and without los of generality (see below), can be taken equal to zero, i.e., $t_{0}=0$.

${ }^{24}$ The measure corresponding to the porbability density $p$ is sometimes referred to as the data generating measure.
} 
From Eqs. (12)-(13) we see that $(x(t), r(t))$ is defined by the following pair of stochastic differential equations

$$
\begin{gathered}
d x=r d t \\
d r=f(r) d t+g(r) d W(t)
\end{gathered}
$$

which implies that the joint PDF obeys the (forward) Fokker-Planck equation (Masoliver, 2018)

$$
\frac{\partial p}{\partial t}=-r \frac{\partial p}{\partial x}-\frac{\partial}{\partial r}[f(r) p]+\frac{1}{2} \frac{\partial^{2}}{\partial r^{2}}\left[g^{2}(r) p\right]
$$

Since $x\left(t_{0}\right)=0$ and $r\left(t_{0}\right)=r_{0}$, the initial condition of this equation is ${ }^{25}$

$$
p\left(x, r, t_{0} \mid r_{0}, t_{0}\right)=\delta(x) \delta\left(r-r_{0}\right)
$$

Let us incidentally note that since $f(r)$ and $g(r)$ do not depend explicitly on time, the process is time homogeneous, that is to say, invaritant under time translations $\left(t \rightarrow t-t_{0}\right)$ and we can, therefore, set $t_{0}=0$ without loss of generality.

There are two different approaches for obtaining the discount function $D(t)$. One of them, which is standard in the financial literature, is based on the backward Fokker-Planck equation and it is called the Feynman-Kac approach (Brigo and Mercurio, 2006; Masoliver, 2018). A second procedure is based on Fourier analysis (Farmer et al., 2015; Masoliver, 2018). Let us next succinctly present both approaches.

\section{Feynman-Kac approach}

The Feynman-Kac approach obtains a partial differential equation for the discount function $D=$ $D\left(t \mid r_{0}\right)$ which is based is the backward Fokker-Planck equation. This equation is called the FeynmanKac equation and reads (see Appendix A for details)

$$
\frac{\partial D}{\partial t}=-r_{0} D+f\left(r_{0}\right) \frac{\partial D}{\partial r_{0}}+\frac{1}{2} g^{2}\left(r_{0}\right) \frac{\partial^{2} D}{\partial r^{2}}
$$

with the initial condition

$$
D\left(0 \mid r_{0}\right)=1
$$

\section{Fourier transform approach}

We have recently presented an alternative method for obtaining the discount function which is based on the use of the characteristic function instead of the PDF and it turns out to be quite advantageous in linear cases (Farmer et al., 2014, 2015). Let us recall that the characteristic function is the Fourier transform of the joint density:

$$
\bar{p}\left(w_{1}, w_{2}, t \mid r_{0}\right)=\int_{-\infty}^{\infty} e^{-i w_{2} r} d r \int_{-\infty}^{\infty} e^{-i w_{1} x} p\left(x, r, t \mid r_{0}\right) d x
$$

One of the chief advantages of working with the characteristic function is that obtaining the effective discount is straightforward. Indeed, comparison of Eq. (15),

$$
D\left(t \mid r_{0}\right)=\int_{-\infty}^{\infty} d r \int_{-\infty}^{\infty} e^{-x} p\left(x, r, t \mid r_{0}\right) d x
$$

with Eq. (21) shows that

\footnotetext{
${ }^{25}$ Recall that the Dirac delta function $\partial(z)$ is a generalized function with $\partial(z)=0$ for $z \neq 0$ and such that

$$
\int_{-\infty}^{\infty} \delta(z) d z=1 \text { and } \int_{-\infty}^{\infty} \delta(z) f(z) d z=f(0),
$$
}

Over any sufficiently well behaved $f(z)$ vanishing as $z \rightarrow \pm \infty$ 


$$
D\left(t \mid r_{0}\right)=\bar{p}\left(w_{1}=-i, w_{2}=0, t \mid r_{0}\right)
$$

Therefore, in order to obtain the discount function we only need to know the joint characteristic function of the bidimensional process $(x, r)$.

\section{Adding risk aversion}

As we have mentioned at the end of Sect. I, the far future is less certain than the near future and we should expect that longer term discount bear greater risk, which would imply higher interest rates. In finance these risk factors are taken into account by considering the so-called "market price of risk" (Vasicek, 1977; Brigo and Mercurio, 2006).

In the context of bond pricing, if investors are risk neutral then there is no market price of risk and prices can be modelled based on the data generating measure $p$ which is obtained by solving the FokkerPlanck equation (17) with initial condition (18). The discount function $D(t)$ is then achieved through the Fourier transform $\bar{p}$ or, alternatively, by solving the Feynman-Kac equation (19) with initial condition (20). This is sometimes called the Local Expectation Hypothesis (Cox, Ingersoll and Ross, 1981; Gilles and Leroy, 1986). However, a more general assumption is that investors are sensitive to risk, in such a case bonds can no longer be priced in this way. Instead they are priced with an artificial probability density function, $p^{*}$, usually called risk-neutral measure. The two measures $p$ and $p^{*}$ are related by the market price of risk, which is the extra return per unit risk that investors demand to bear risk. This additional return is given by a quantity $q=q(r, t)$ that in its most general form may depend on the rate $r$ and current time $t$. Although the most usual assumption is that $q=q(r)$ only depends on the rate (Vasicek, 1977). Following a standard procedure for bond pricing (Vasicek, 1977; Piazzesi, 2009, see also Appendix B for a short review) one takes risk into account with the drift replacement $f(r) \rightarrow f^{*}(r)$, being

$$
f^{*}(r)=f(r)+g(r) q(r)
$$

where $q(r) \geq 0$ is the market price of risk. ${ }^{26}$ In this case the risk neutral measure $p^{*}\left(x, r, t \mid r_{0}\right)$ will be given by the Fokker-Planck equation (17) with $f(r)$ replaced by $f^{*}(r)$, that is,

$$
\frac{\partial p^{*}}{\partial t}=-r \frac{\partial p^{*}}{\partial x}-\frac{\partial}{\partial r}\left[[f(r)+g(r) q(e)] p^{*}\right]+\frac{1}{2} \frac{\partial^{2}}{\partial r^{2}}\left[g^{2}(r) p^{*}\right]
$$

with initial condition given by Eq. (18). In an analogous way, the discount function, adjusted for risk, will now be given by de Feynman-Kac equation (19) with $f(r)$ replaced by $f^{*}(r)$. Using the Fourier method the discount function will be given in terms of the risk-neutral characteristic function, $\bar{p}^{*}\left(w_{1}, w_{2}, t \mid r_{0}\right)$, by [cf. Eq. (22)]

$$
D\left(t \mid r_{0}\right)=\bar{p}^{*}\left(w_{1}=-i, w_{2}=0, t \mid r_{0}\right)
$$

\section{SOME MODELS}

Financial economists have developed a large number of models of interest rate processes to enable them to price bonds and other cash flows. In these models interest rates are described by positive random processes since financial interest rates never (or very rarely) go negative. Although the models could in principle be extended to arbitrary horizons, they have only been studied carefully over time horizons of up to 30 years, since bonds are hardly ever issued for periods longer than this.

On the other hand, environmental economists are interested in the real behavior of the economic growth over much larger horizons, in contrast to financial economists, who are typically more interested in nominal rates over shorter horizons. The large-horizon behavior of growth is essentially different to that of the short-horizon behavior and this is due to the fact that real rates can take on negative values. Indeed, taking nominal rates corrected by inflation as a proxy of economic growth, we have recently

\footnotetext{
${ }^{26}$ The form of $q(r)$ is, in principle, unknown and has to be conjectured. The usual and simplest assumption is that $q(r)=q$ is constant. In such a case the value of $q$ is estimated from empirical data.
} 
shown (Farmer et al., 2014) thorough an empirical study on many countries that real interest rates are negative around $25 \%$ of the time (see Sect. (IV).

To understand how discounting depends on the random process used to characterize interest rates we have studied three different models and obtained exact analytical expressions for the discount function (Farmer et al., 2015). The three models describe to varying degree a number of relevant characteristics observed in rates, while being simple enough to allow for complete analytical treatment.

The first model is based on the Ornstein-Uhlenbeck process (called Vasicek model in financial literature) which allows for negative rates and is therefore suitable for pricing environmental problems. The model has a stationary probability distribution and exhibits reversion to the mean, which means that the process tends to recur to its average stationary value. The second and third models considered are given by the Feller and log-normal processes respectively. For these processes rates cannot be negative. The Feller process --also known as Cox Ingersoll and Ross (CIR) model- has reversion to the mean and a stationary probability distribution and it is one of the most popular models in finance. On the other hand, the log-normal process (Dotham model) does not have reversion to the mean and does not have a stationary distribution. Despite these shortcomings the Dotham model has also been used in the financial literature mainly because rates are positive and allows for analytical treatment (Brigo and Mercurio, 2006). Let us next briefly review these models and summarize their main traits.

\subsection{The Vasicek model}

In this model rates are described by the Ornstein-Uhlenbeck process (Vasicek, 1977), which is characterized by linear drift and constant noise intensity:

$$
d r(t)=-\alpha[r(t)-m]+k d W(t)
$$

where $r(t)$ is the rate and $W(t)$ the Wiener process. The parameter $m$, sometimes refereed to as "normal level," is a mean value to which rates revert, $k>0$ is the amplitude of fluctuations, and $\alpha>0$ is the strength of the reversion to the mean. As we will see in the next section these parameters can be estimated from empirical data.

The model is Gaussian and has a stationary probability distribution (as $t \rightarrow \infty$ ) given by (Gardiner, 1986; Masoliver, 2018)

$$
P_{S}(r)=\left(\frac{\alpha}{\pi k^{2}}\right) e^{-\alpha(r-m)^{2} / k^{2}}
$$

which proves that the normal level $m$ is the stationary mean value

$$
m=\mathbb{E}[r(t)]
$$

It can also be shown that the correlation function of the process, defined as the average

$$
C(\tau)=\mathbb{E}[r(t+\tau) r(t)]-(\mathbb{E}[r(t)])^{2}
$$

in the stationary state reads (Masoliver, 2018)

$$
C(\tau)=\left(\frac{k^{2}}{2 \alpha}\right) e^{-\alpha \tau}
$$

which means that $\alpha^{-1}$ is the correlation time of the rate. Let us observe that the volatility, $\sigma^{2}=C(0)$, is independent of the normal level and given by

$$
\sigma^{2}=k^{2} / 2 \alpha
$$

For this model it is possible to obtain an exact expression for the discount function $D(t)$ that reads (Farmer et al., (2015), see also Masoliver (2018))

$$
\begin{gathered}
\ln D(t)=-\frac{r_{0}}{\alpha}\left(1-e^{-\alpha t}\right)+\frac{k^{2}}{2 \alpha^{3}}\left[a t-2\left(1-e^{-\alpha t}\right)+\frac{1}{2}\left(1-e^{-2 \alpha t}\right)\right]-m[t \\
\left.-\frac{1}{\alpha}\left(1-e^{-\alpha t}\right)\right]
\end{gathered}
$$


where $r_{0}=r(0)$ is the initial rate. Note that the exponential terms in Eq. (30) are only significant at small times, that is to say, for times smaller than the correlation time of the rate $\left(t<\alpha^{-1}\right)$ but they are negligible at longer times. Neglecting also constant terms we thus have

$$
D(t) \simeq e^{-r \infty t}
$$

where

$$
r_{\infty}=m-\frac{k^{2}}{2 \alpha^{2}}
$$

is the long-run discount rate. Let us note an important fact that the long-run discount rate is smaller than the mean value of the return given by the normal level $m$. This reduction is quantified by the ratio $k / \alpha$, which means, for instance, that long persistence (recall that this is equivalent to long correlation time, i.e., $\alpha$ small) or else increasing noise fluctuations (i.e., $k$ large) decrease the long-run discount rate as compared with the average rate.

\subsubsection{Risk aversion}

As mentioned above risk aversion is taken into account by introducing the market price of risk $q(r)$ and changing drift according to Eq. (23). For the Vasicek model, in which $f(r)=-\alpha(r-m)$ and $g(r)=k$, we have

$$
f^{*}(r)=-\alpha(r-m)+k q(r)
$$

and taking $q$ constant, we write

$$
f^{*}(r)=-\alpha\left(r-m^{*}\right)
$$

where

$$
m^{*}=m+\frac{q k}{\alpha}
$$

Since the modified drift $f^{*}(r)$ has the same form that $f(r)$ we conclude that the adjusted-for-risk discount function will be given by Eq. (30) after the replacement $m \rightarrow m^{*}$. In particular, the adjusted long-run discount $r^{*}$ now reads [cf. Eq. (32)]

$$
r_{\infty}^{*}=m+\frac{q k}{\alpha}-\frac{k^{2}}{2 \alpha^{2}}
$$

Thus we see that the long-run discount depends on the historical rate $m$ but shifted by two terms. The first term raise the long-run rate due to the market price of risk. The second shift lowers it by an amount given by the ratio of uncertainty (as measured by $k$ ) and persistence (as measured by $\alpha$ ). We can trivially rewrite the equation above as

$$
r_{\infty}^{*}=m+\frac{k}{\alpha}\left(q-\frac{k}{2 \alpha}\right)
$$

This expression clearly shows that the overall shift in the long-run discount rate will be positive or negative depending on the size of the market price of risk $q$ in relation to the ratio $k / 2 \alpha$ of the noise intensity $k$ and the reversion rate $1 / \alpha$.

It is not surprising that the market price of risk raises the long term rate, but it is not so obvious that uncertainty and persistence (through the combination $k / 2 \alpha$ ) can lower $r_{\infty}$. Indeed, for the OrnsteinUhlenbeck process uncertainty and persistence can make the long term rate arbitrarily small. Certainly for any given mean interest rate $m$, by varying $k$ and $\alpha$, the long-run discount rate $r_{\infty}$ can take on any value less than $m$, including negative values, while at the same time the standard deviation $\sigma$ can also be made to take on any arbitrary positive value.

It is even possible for the long-run rate to be negative. This is due to the amplification of negative real interest rates $r(t)$. Computation of the discount function involves an average over exponentials, 
rather than the exponential of an average. As a result, periods where interest rates are negative are amplified, and can easily dominate periods where interest rates are large and positive, even if the negative rates are rarer and weaker. It does not take many such periods to substantially reduce the long run interest rate.

To summarize in the Vasicek model, and even taking into account risk aversion, the long-run discounting rate can be much lower than the mean, and can correspond to low interest rates that are rarely observed.

\subsection{CIR model}

In this model rates are described by the Feller process (Cox, Ingersoll, Ross, 1985). The process is a diffusion process with linear drift and linear diffusion coefficient (Feller, 1951),

$$
d r(t)=-\alpha[r(t)-m] d t+k \sqrt{r(t)} d W(t)
$$

where, as in the Ornstein-Uhlenbeck process, $m>0$ represents the mean stationary rate and $\alpha^{-1}$ is the correlation time. It can be shown that the Feller process never attains negative values (Feller, 1951; Masoliver and Perelló, 2012; Masoliver, 2018) and it is, therefore, suitable for modeling financial nominal rates rather than real rates. The process is not Gaussian and stationary density is given by the Gamma distribution (Masolover, 2018)

$$
p_{s}(r)=\frac{\left(\frac{2 \alpha}{k^{2}}\right)^{\theta}}{\Gamma(\theta)} r^{\theta-1} e^{-\left(\frac{2 \alpha}{k^{2}}\right) r}
$$

where

$$
\theta=\frac{2 \alpha m}{k^{2}}
$$

is a positive constant that combines all the parameters of the model into a single dimensionless expression. As in the Vasicek model $m$ is the stationary mean value at which the process reverts. (2018)

The stationary correlation function is also given by an exponential decreasing in time (Masoliver,

$$
C(\tau)=\left(\frac{m k^{2}}{2 \alpha}\right) e^{-\alpha \tau}
$$

Note that $\alpha^{-1}$ is again the correlation time but, contrary to the Vasicek model, the volatility $\sigma^{2}=$ $m k^{2} / 2 \alpha$ depends on the normal level $m$ as well.

For the CIR model it is also possible to obtain the exact expression for the discount function. The result reads (Brigo and Mercurio, 2006; Farmer et al., 2015)

$$
D(t)=\left[\frac{2 \lambda e^{-(\lambda-\alpha) t / 2}}{(\lambda+\alpha)+(\lambda-\alpha) e^{-\lambda t}}\right]^{\theta} \exp \left\{-\frac{2\left(1-e^{\lambda t}\right) r_{0}}{(\lambda+\alpha)+(\lambda-\alpha) e^{-\lambda t}}\right\}
$$

where $r_{0}$ is the initial rate, $\theta$ is defined in Eq. (39), and

$$
\lambda=\sqrt{\alpha^{2}+2 k^{2}}
$$

Notice that $\lambda>\alpha$ and the time scale represented by $\lambda^{-1}$ is smaller than the correlation time $\alpha^{-1}$. As time increases (in fact, when $\lambda \gg 1$ ) the effective discount (40) reduces to

$$
D(t) \simeq e^{-r \infty t}
$$

$(t \rightarrow \infty)$, where

$$
r_{\infty}=\frac{1}{2}(\lambda-\alpha) \theta
$$


is the long-run discount rate of the CIR model. Substituting for Eqs. (39) and (41) this can be written as

$$
r_{\infty}=\frac{2 m}{1+\sqrt{1+2 k^{2} / \alpha^{2}}}
$$

which clearly shows that

$$
r_{\infty}<m
$$

Therefore, like the Vasicek model, the CIR long-run discount rate is smaller than the stationary average rate by an amount that also depends on the square of the ratio $k / \alpha$. Notice that, again, either a long persistence ( $\alpha$ small) or an increase of the noise intensity ( $k$ large) diminish the long-run discount rate.

\subsubsection{Risk aversion}

For the Feller process [ef. Eq. (38)] $f(r)=-\alpha(r-m)$ and $g(r)=k \sqrt{r}$ and the adjusted drift is

$$
f^{*}(r)=-\alpha(r-m)+k q(r) \sqrt{r}
$$

For any function $q(r)$ (including a constant market price of risk) this leads to an unsolvable FokkerPlanck equation with no analytical expression for the adjusted discount and the long-run discount rate. It is, nonetheless, possible to get analytical expressions for these quantities if the market price of risk has the functional form

$$
q(r)=q \sqrt{r}
$$

where $q \geq 0$ is a positive quantity. In such a case we may write

$$
f^{*}(r)=-\alpha^{*}\left(r-m^{*}\right)
$$

where

$$
\alpha^{*}=\alpha-k q, \quad m^{*}=\frac{\alpha m}{\alpha-k q}
$$

The adjusted drift has the same form than $f(r)$. Therefore, the adjusted discount function will be given Eq. (40) with the replacements $\alpha \rightarrow \alpha^{*}$ and $m \rightarrow m^{*}$ and the long-run discount is [cf. Eq. (44)]

$$
r_{\infty}^{*}=\frac{2 m^{*}}{1+\sqrt{1+2 k^{2} / \alpha^{* 2}}}
$$

From the definitions of $\alpha^{*}$ and $m^{*}$ we easily see that $\alpha^{*} \leq \alpha$ and $\alpha^{*} m^{*}=a m$. Hence, writing $r_{\infty}^{*}$ as

$$
r_{\infty}^{*}=\frac{2 \alpha^{*} m^{*}}{\alpha^{*}+\sqrt{\alpha^{* 2}+2 k^{2}}}
$$

we see at once that $r_{\infty}^{*} \geq r_{\infty}$. We therefore conclude that if the market price of risk has the special functional for given by Eq. (46), in the CIR model risk always increases the long-run discount rate regardless noise intensity and persistence.

\subsection{The log normal model}

In this mode rates are described by the geometric Brownian notion (log-normal process). It can be written as

$$
\frac{d r}{r}=\alpha d t+k d W(t)
$$

where $r$ is the interest rate, $\alpha$ and $k$ are constant parameters, $\alpha$ maybe positive or negative whereas $k$ is always positive and $W(t)$ is the Wiener process. Equation (50) can be integrated at once yielding 


$$
r(t)=r_{0} \exp \left\{\left(\alpha-\frac{k^{2}}{2}\right) t+k W(t)\right\}
$$

showing that $r(t)$ is never negative $\left(r_{0}>0\right)$. Therefore, the log-normal is more suited for modelling nominal interest rates in finance, which are never negative, than for modelling real rates in environmental economics. Contrary to OU and Feller processes, the log-normal process does not show reversion to the mean. Indeed, as $t$ increases we see from Eq. (51) that the rate either diverges when $\alpha>0$ or goes to zero if $\alpha<0$. In an equivalent way one can also show from Eq. (51) that the mean and variance of the process are

$$
\langle r(t)\rangle=r_{0} e^{\alpha t}, \quad \operatorname{Var}[r(t)]=r_{0}^{2} e^{2 \alpha t}\left(e^{k^{2} t}-1\right)
$$

The discount associated with the log-normal process model was studied by Dothan (1978) and in finance is sometimes known as the Dothan model. It is one of the models used in the literature (Brigo and Mercurio, 2006) mostly because allows for analytical treatment. In Farmer et al. (2015) we have obtained the discounting function and discussed some of its interesting asymptotic properties. We will here briefly summarize the main results and refer the interested reader to our previous work for more details.

Contrary to Vasicek and CIR models, where it is possible to obtain exact expressions for the discount function $D(t)$, in the log-normal case we can only obtain the exact expression for the Laplace transform,

$$
\widehat{D}(s)=\int_{0}^{\infty} e^{-s} D(t) d t
$$

of the discount. The resulting formula -written as an integral of the Kummer function- is rather intricate and we won't write it here (see Farmer at al., 2015, for more information). From that expression we can, nonetheless, get asymptotic expressions as $t \rightarrow \infty$ for discount in real time using the so-called Tauberian theorems which relate the small $s$ behaviour of $\widehat{D}(s)$ with the long-time behaviour of $D(t)$ (Pitt, 1958). The final result are the following asymptotic expressions of the discount function $D(t)$ as $t \rightarrow \infty$ which for long-run discount is all that matters (Farmer et al., 2015):

$$
D(t) \sim \begin{cases}\text { constant } & \alpha<k^{2} / 2 \\ e^{-r_{\infty} t} & \alpha>k^{2} / 2 \\ t^{-1 / 2} & \alpha=k^{2} / 2\end{cases}
$$

The asymptotic form of the discount function thus depends on the values taken by the ratio $\alpha / k^{2}$ between the strength of the deterministic drift $\alpha$ and the amplitude of fluctuations given by $k^{2} / 2$.

i) The case $\alpha<k^{2} / 2$ corresponds to strong fluctuations, where the noise intensity $k^{2} / 2$ is greater than the drift parameter $\alpha$. In this case the discount asymptotically approximates to a constant value (see Farmer et al., 2015, for the actual value of this constant).

ii) The case $\alpha>k^{2} / 2$ corresponds to mild fluctuations for which deterministic drift is stronger than noise. In such a case the discount function has the expected exponential decay (Farmer et al., 2015)

$$
D(t) \sim e^{r_{\infty} t}
$$

with a long-run rate of discount given by

$$
r_{\infty}=\frac{1}{\delta}\left(\alpha-\frac{k^{2}}{2}\right)
$$

where $0<\delta<1$ is a positive numerical factor which only depends on the ratio

$2 \alpha / k^{2}$ and reads

$$
\delta=\psi\left(\frac{2 \alpha}{k^{2}}\right)+\frac{1}{\frac{2 \alpha}{k^{2}}-1}
$$

where $\psi($.$) is the digamma function.$ 
Let us write Eq. (53) in a more suggestive form. Indeed, from Eq. (51) we see that

$$
\mathbb{E}\left[\ln \frac{r(t)}{r_{0}}\right]=\left(\alpha-\frac{k^{2}}{2}\right) t
$$

and with the help of Eq. (54) we write Eq. (53) as

$$
D(t) \sim \exp \left\{-\frac{1}{\delta} \mathbb{E}\left[\ln \frac{r(t)}{r_{0}}\right]\right\}
$$

$\left(t \rightarrow \infty\right.$ and $\left.k^{2} / 2<\alpha\right)$. Note that the average $\mathbb{E}\left[\ln r(t) / r_{0}\right]$ is what a practitioner would take as an estimate of the discount rate up to time $t$ within the log-normal model. Since $0<\delta<1$, the analytical result (56) shows that the actual long-run rate of the model is a fraction of the average rate. We have shown elsewhere that the long-run discount rate is at most $73 \%$ of the average rate (Farmer et al., 2015). In this way when $\frac{2 \alpha}{k^{2}}>1$ the log-normal model follows a similar pattern to that of the OU and Feller models: In all of them the long-run rate is smaller than the average rate. This general statement is in fact a direct consequence of Jenesen's inequality, which states that the average of a convex function is greater than or equal to the function of the average; that is, $\mathbb{E}[f(X)] \geq f(\mathbb{E}[X])$. Assuming $f$ to be the decreasing exponential and $X$ the cumulative process $x(t)$ defined in Eq. (13), it follows immediately that the long-run rate $r_{\infty}$ must be always less than or equal to the average rate. Nonetheless, our procedure quantifies the difference among averages (Farmer et al., 2015).

iii) The critical case $\alpha=k^{2} / 2$, in which deterministic motion and fluctuations are balance, leads to the hyperbolic discount function as obtained by Farmer and Geanakoplos (2009). The hyperbolic $D(t)$ is substantially greater than any exponential decaying function, showing that there is no long-run rate of interest in this case. In fact the long-run rate of interest is 0 , but that does not convey as precise information as saying $D(t)$ is approximately $k / \sqrt{t}$ for all large $t$. Since the sum (i.e., the integral) of all these $D(t)$ is infinite, such $D(t)$ assigns infinite value to any permanent positive flow of consumption. In other words, the infinite future is infinitely valuable.

\subsubsection{Risk aversion}

Let us very briefly comment on the inclusion of risk aversion in the Dothan model. For the lognormal process $f(r)=\alpha r$ and $g(r)=k r$ and

$$
f^{*}(r)=[\alpha+k q(r)] r
$$

Assuming a constant market price of risk, $q(r)=q \geq 0$, we have

$$
f^{*}(r)=\alpha^{*} r, \quad \alpha^{*}=\alpha+q
$$

Again $f^{*}(r)$ has the same form than $f(r)$ and all previous results will apply with the replacement $\alpha \rightarrow \alpha^{*}$.

\section{EMPIRICAL STUDY}

To understand how discounting depends on the random process used to characterize interest rates, we have collected data for nominal interest rates and inflation for nine countries over spans of time ranging from 87 to 318 years. The countries in our sample are: Argentina (ARG, 1864-1960), Australia (AUS, 1861-2012), Canada (CAN, 1913-2012), Denmark (DNK, 1821-2012), United Kingdom (GBR, 1694-2012), Netherlands (NLD, 1813-2012), Sweden (SWE, 1868-2012), the United States (USA, 1820-2012), and South Africa (ZAF, 1920-2012) (see Table 1). Since all but two of our nominal interest rate processes are for ten year government bonds, which pay out over a ten year period, we smooth inflation rates with a ten year moving average, and subtract the annualized inflation index from the annualized nominal rate to compute the real interest rate. 
Table 1

List of the data analyzed.

\begin{tabular}{|c|c|c|c|c|c|c|}
\hline & Country & Consumer Price Index & Bond Yields & from & to & records \\
\hline 1 & Canada & $\begin{array}{l}\text { CPCANM } \\
\text { quarterly }\end{array}$ & $\begin{array}{l}\text { IGCAN10 } \\
\text { quarterly }\end{array}$ & $12 / 31 / 1913$ & $09 / 30 / 2012$ & 357 \\
\hline 2 & Argentina & $\begin{array}{l}\text { CPARGM } \\
\text { annual from 12/31/1864 } \\
\text { quarterly from 12/31/1932 }\end{array}$ & $\begin{array}{l}\text { IGARGM } \\
\text { quarterly }\end{array}$ & $12 / 31 / 1864$ & $03 / 31 / 1960$ & 342 \\
\hline 3 & Nerherlands & $\begin{array}{l}\text { CPNLDM } \\
\text { annual }\end{array}$ & $\begin{array}{l}\text { IGNLD10D } \\
\text { annua }\end{array}$ & $12 / 31 / 1813$ & $12 / 31 / 2012$ & 189 \\
\hline 4 & Australia & $\begin{array}{l}\text { CPAUSM } \\
\text { annual from 12/31/1861 } \\
\text { quarterly } 12 / 31 / 1991\end{array}$ & $\begin{array}{l}\text { IGAUS10 } \\
\text { quarterly }\end{array}$ & $12 / 31 / 1961$ & 09/30/2012 & 564 \\
\hline 5 & Denmark & $\begin{array}{l}\text { CPDNKM } \\
\text { annual from 12/31/1821 } \\
\text { quarterly from 12/31/1914 }\end{array}$ & $\begin{array}{l}\text { IGDNK10 } \\
\text { quarterly }\end{array}$ & $12 / 31 / 1821$ & 09/30/2012 & 725 \\
\hline 6 & South Africa & $\begin{array}{l}\text { CPZAFM } \\
\text { quarterly }\end{array}$ & $\begin{array}{l}\text { IGZAF10 } \\
\text { quarterly }\end{array}$ & $12 / 31 / 1920$ & 09/30/2012 & 329 \\
\hline 7 & Sweden & $\begin{array}{l}\text { CPSWEM } \\
\text { annual }\end{array}$ & $\begin{array}{l}\text { IGSWE10 } \\
\text { annual }\end{array}$ & $12 / 31 / 1868$ & $12 / 31 / 2012$ & 135 \\
\hline 8 & United Kingdom & $\begin{array}{l}\text { CPGBRM } \\
\text { annual }\end{array}$ & $\begin{array}{l}\text { IDGBRD } \\
\text { annual }\end{array}$ & $12 / 31 / 1694$ & $12 / 31 / 2012$ & 309 \\
\hline & United States & $\begin{array}{l}\text { CPUSAM } \\
\text { annual }\end{array}$ & $\begin{array}{l}\text { TRUSG10M } \\
\text { annual }\end{array}$ & $12 / 31 / 1820$ & $10 / 30 / 2012$ & 183 \\
\hline
\end{tabular}

Recall that real rate are nominal rates corrected by inflation, therefore, in order to estimate real rates we must estimate nominal rates as well as inflation rate. For one hand, nominal rate $n(t)$ are determined by IG rates constructed from de 10 year Government Bond Yield $y(t \mid \tau)$ with $\tau=10$ years. The latter is defined as follows. Let us denote by $B(t \mid t+\tau)$ the price at time $t$ of a government bond maturing at time $t+\tau$ with unit maturity, $B(t \mid t)=1$, then the yield $y(t \mid \tau)$ is defined as

$$
y(t \mid \tau)=-\ln B(t \mid t+\tau) / \tau
$$

so that

$$
B(t \mid t+\tau)=e^{\tau y(t \mid \tau)}
$$

Nominal rates are then estimated by

$$
n(t) \sim y(t \mid \tau), \quad(\tau=10 \text { years })
$$

On the other hand, the inflation rate is estimated through the Consumer Price Index (CPI) as

$$
i(t) \sim \frac{1}{\tau} \ln [I(t+\tau) / I(t)]
$$

where $I(t)$ is the aggregated inflation up to time $t$, and $\tau=10$ years and whose relation with the Consumer Price Index (CPI) is

$$
I(t+\tau)=I(t) \prod_{j=0}^{\tau-1}[1+C(t+j)]
$$


Table 2

Parameter estimation of the Vasicek model (using real rates) in yearly units.

\begin{tabular}{lccccccccc}
\hline Country & Neg RI & $\boldsymbol{m}$ & Min & Max & $\boldsymbol{k}$ & Min & Max & $\boldsymbol{\alpha}$ & $\boldsymbol{r}_{\infty}$ \\
\hline Canada & $22 \%(20 y)$ & 2.9 & 0.1 & 6 & 2.3 & 1.1 & 2.0 & 0.26 & 2.5 \\
Argentina & $20 \%(17 y)$ & 2.4 & -2.9 & 6.8 & 6.2 & 2.8 & 6.7 & 0.39 & 1.1 \\
Netherlands & $17 \%(33 y)$ & 3.2 & 0.8 & 5.4 & 1.6 & 0.8 & 2.2 & 0.14 & 2.4 \\
Australia & $23 \%(33 y)$ & 2.6 & -0.7 & 4.9 & 2.3 & 0.7 & 2.8 & 0.19 & 1.9 \\
Denmark & $18 \%(33 y)$ & 3.2 & 1.5 & 4.3 & 2.3 & 1.1 & 2.9 & 0.23 & 2.7 \\
South Africa & $43 \%(36 y)$ & 1.8 & -2.2 & 5.5 & 2.5 & 1.2 & 2.0 & 0.21 & 1.1. \\
Sweden & $28 \%(38 y)$ & 2.3 & -0.3 & 3.9 & 2.5 & 0.6 & 3.4 & 0.25 & 1.9 \\
United Kingdom & $14 \%(45 y)$ & 3.3 & 1.4 & 4.3 & 1.9 & 1.0 & 2.4 & 0.19 & 2.8 \\
United States & $31 \%(36 y)$ & 2.6 & 1.0 & 4.0 & 1.8 & 1.2 & 2.1 & 0.18 & 2.1 \\
\hline Stable countries & $23 \%(33 y)$ & 2.7 & -0.14 & 5.0 & 2.6 & 1.04 & 2.94 & 0.23 & 2.1 \\
\hline
\end{tabular}

Notes (i) "Neg Rl" gives the percentage of time and the total number of years in which real interest rates are negative. (ii) The columns $m, k$ (in \%) and $\alpha$ are estimates taking each country time series; $r_{\infty}$ (in \%) is evaluated from Eq. (32). (iii) The Min and Max columns illustrate the robustness of the estimation procedure by providing the minimum and the maximum value of parameter estimation on four equal length data blocks. (iv) $\alpha$ is estimated by fitting the empirical correlation function to an exponential (cf. Eq. (28)) after using the whole data block.

where $C(t)$ is the time series of the empirical CPI. The instantaneous rate of inflation $i(t)$ is, therefore, estimated by the quantity $i(t+\tau)(\tau=10$ years) which written in terms of the CPI reads

$$
i(t) \sim i(t+\tau)=\frac{1}{\tau} \sum_{j=0}^{\tau-1} \ln [1+C(t+j)]
$$

Finally, real interest rate $r(t)$ are defined via Fisher's procedure, subtracting realized inflation from nominal interest rates:

$$
r(t)=n(t)-i(t)
$$

Having established how to estimate real rates from data, let us now proceed to present our empirical estimates of the long discount rate for the 9 countries shown in Table 2. Let us first notice that a striking feature observed in many epochs for all countries is that real interest rates frequently become negative, often by substantial amounts and for long periods of time (see Table 2). On average, real interest rates are negative one quarter of the time. This makes the CIR and Dothan models less interesting for modelling real interest rates, as well as many other models which assume that interest rates are positive (Brigo and Mercurio, 2006). We, therefore, confine the empirical work to the Vasicek model. We also assume the "Local Expectation Hypothesis" according to which we live in a risk neutral world and the market price of risk is zero. This is obviously a first approximation, specially for long-run discounting. ${ }^{27}$

We estimate the parameters $m, \alpha$ and $k$ of the Vasicek model to each of the data series. The parameter $m$ is easily estimated because it is the stationary mean value of the rate [cf. Eq. (27)]

$$
m=\mathbb{E}[r(t)]
$$

The estimation of parameters $\alpha$ and $k$ is based on the correlation function of the Ornstein-Uhlenbeck process. Thus from Eq. (28) we have

$$
C\left(t-t^{\prime}\right)=\frac{k^{2}}{2 \alpha} e^{-\alpha\left|t-t^{\prime}\right|}
$$

Evaluating then the empirical correlation from data and fitting it by an exponential we estimate $\alpha$ (measured in year units) for each country. The third and last parameter, $k$, is obtained from the empirical standard deviation $\sigma^{2}=\mathbb{E}\left[|r(t)-m|^{2}\right]$, which for the Vasicek model is given by Eq. (29). That is,

\footnotetext{
${ }^{27}$ Adding risk, after assuming a constant market price of risk, is under current investigation (Farmer et. al. 2019)
} 


$$
k=\sigma \sqrt{2 \alpha}
$$

The resulting parameters for all countries are listed in Table 2 along with its maximum and minimum value for each country.

Once the parameters of the Vasicek model have been estimated, the long-run discount rate is readily evaluated from Eq. (32),

$$
r_{\infty}=m-k^{2} / 2 \alpha^{2}
$$

We finish this section by recalling that we have termed the nine countries analyzed as "stable countries" because they have not suffered periods of destabilizing inflation (as, for instance, Germany and Japan among others) and consequently show stable and frequently positive real interest rates which in turn results in positive long-run rates. ${ }^{28}$

\section{CONCLUDING REMARKS}

Financial economists have developed a large number of models of interest rate processes to enable them to price bonds and other cash flows. In these models interest rates are described by positive random processes since financial interest rates never (or very rarely) go negative. Although the models could in principle be extended to arbitrary horizons, they have only been studied carefully over time horizons of up to 30 years, since bonds are seldom issued for periods longer than this.

On the other hand, environmental economists are interested in the real behavior of the economic growth over much larger horizons, in contrast to financial economists, who are typically more interested in nominal rates over shorter horizons. Their behavior is essentially different due to the fact that real rates can take on negative values. Taking nominal rates corrected by inflation as a proxy of economic growth, we have seen from an empirical survey on 9 relatively stable countries that real interest rates are negative around $23 \%$ of the time.

To understand how discounting depends on the random process used to characterize interest rates we have studied three different models and obtained exact analytical expressions for the discount function. These three models describe to varying degrees a number of relevant characteristics observed in rates, while being simple enough to allow for complete analytical treatment.

In the first model rates are represented by the Ornstein-Uhlenbeck process (Vasicek model) which allows for negative rates and is therefore suitable for pricing environmental problems. The model has a stationary probability distribution and exhibits reversion to the mean indicating that the process tends to recur to its average stationary value.

In the second and third models considered rates are represented by the Feller and log-normal processes respectively. For these processes rates cannot be negative. The Feller process (CIR model) has reversion to the mean and a stationary probability distribution constituting one of the most popular models in finance. On the other hand, the log-normal process (Dotham model) has no reversion to the mean nor stationary distribution.

We have carried out an empirical study of real rates and bearing in mind that real interest rates may be negative we have in consequence used the Vasicek model. When we estimate the parameters of the Vasicek model -that is $m, \alpha$ and $k$, assuming no risk aversion- of the nine countries which never faced destabilizing inflation, we find an average historical rate $m=2.7 \%$ whereas, due to fluctuations, the long-run discounting has an average of $r_{\infty}=2.1 \%$, which is around $22 \%$ smaller than the historical average represented by $m$. Let us incidentally note that our value of $2.1 \%$ is closer to Stern's estimate $(1.4 \%)$ than that of Nordhhaus (4\%).

It is also worth mentioning the case of the United Kingdom where the historical rate over more than 300 years is $3.3 \%$ while the long-run discount rate is $r_{\infty}=2.8 \%$ (see Table 2). This long-run discount is very close to the one recently obtained by Giglio, Maggiori and Stroebel (2015) who, using data on

\footnotetext{
${ }^{28}$ A more complete study including non stable countries in which the long-run discount rate is negative togetherwith other characteristics is under present investigation and some results will soon appear (Perelló et. al. 2019).
} 
housing markets in the United Kingdom during 2004-2013 and Singapore during 1995-2013, have estimated an annual discount rate of $2.6 \%$ for payments more than 100 years in the future.

Let us finally recall that present analysis has been performed assuming the "Local Expectation Hypothesis" according to which the data generating measure is equal to the risk-neutral measure implying that the market price of risk $q$ is taken to be zero. In part this is due to the fact that estimating $q$ from data is rather unreliable because one would need to know the instantaneous rate of return (see Appendix B) which we can only approximate from data using the shortest rate available which is the three-month treasury bills. Unfortunately historical data on this shorter bonds is unavailable for most countries. We are, nonetheless, working on this aspect for UK and USA, the only countries for which we have data on three-month treasury bills (Farmer et al., 2019).

We finish with the following reflection aimed at environmental concerns and with which we had finished one of our papers on the problem (Farmer et al., 2014): "Real interest rates are typically closely related to economic growth, and economic downturns are a reality. The great depression lasted for 15 years, and the fall of Rome triggered a depression in Western Europe that lasted almost a thousand years. In light of our results here, arguments that we should wait to act on global warming because future economic growth will easily solve the problem should be viewed with some skepticism. When we plan for the future we should always bear in mind that sustained economic downturns may visit us again, as they have in the past".

\section{Appendix A. The Feynman-Kac equation}

In this appendix we show how obtaining the Feynman-Kac equation (19) for the effective discount function $D\left(t \mid r_{0}\right)$. The procedure, known as Feynman-Kac approach, is based on the Fokker-Planck equation for the PDF $p\left(x, t, t \mid x_{0}, r_{0}, t_{0}\right)$ but in its backward version (see below). In what follows we will assume that $t_{0} \neq 0$ and also that $x_{0}=x\left(t_{0}\right) \neq 0.29$

The backward Fokker-Planck equation ((Masoliver, 2018) corresponding to the forward equation (17) is

$$
\frac{\partial p}{\partial t_{0}}=-r_{0} \frac{\partial p}{\partial x_{0}}-f\left(r_{0}\right) \frac{\partial p}{\partial r_{0}}-\frac{1}{2} g^{2}\left(r_{0}\right) \frac{\partial^{2} p}{\partial r_{0}^{2}}
$$

This equation has to solved with the "final condition" as $t_{0} \rightarrow t$ :

$$
p\left(x, r, t \mid x_{0}, r_{0}, t\right)=\delta\left(x-x_{0}\right) \delta\left(r-r_{0}\right)
$$

We know that the problem is invariant under translations of both time and variable $x_{0}$, that is to say

$$
p\left(x, r, t \mid x_{0}, r_{0}, t_{0}\right)=p\left(x-x_{0}, r, t-t_{0} \mid r_{0}\right)
$$

We thus define the new variables

$$
t^{\prime}=t-t_{0}, \quad x^{\prime}=x-x_{0}
$$

so that

$$
\frac{\partial p}{\partial t_{0}}=-\frac{\partial p}{\partial t^{\prime \prime}}, \quad \frac{\partial p}{\partial x_{0}}=-\frac{\partial p}{\partial x^{\prime}}
$$

and (A1) reads

$$
\frac{\partial p}{\partial t^{\prime}}=-r_{0} \frac{\partial p}{\partial x^{\prime}}+f\left(r_{0}\right) \frac{\partial p}{\partial r_{0}}+\frac{1}{2} g^{2}\left(r_{0}\right) \frac{\partial^{2} p}{\partial r_{0}^{2}}
$$

Note that in this notation the final condition (A2) becomes the initial condition:

\footnotetext{
${ }^{29}$ Note that by definition $x_{0}=0$ (cf. Eq. (13)), however we for the moment keep $x_{0} \neq 0$ and set $t_{0}=0$ and $x_{0}=0$ when needed.
} 


$$
p\left(x^{\prime}, r, t^{\prime}=0 \mid r_{0}\right)=\delta\left(x^{\prime}\right) \delta\left(r-r_{0}\right)
$$

The essential idea of the Feynman-Kac approach consists in using the backward equation (A4) to obtain an equation for the discount function defined in Eq. (15):

$$
D\left(t^{\prime} \mid x_{0}\right)=\int_{-\infty}^{\infty} d r \int_{-\infty}^{\infty} e^{-x^{\prime}} p\left(x^{\prime}, r, t \mid r_{0}\right) d x^{\prime}
$$

In effect, we multiply Eq. (A4) by $e^{-x^{\prime}}$ and integrate over $x^{\prime}$ and $r$, we have

$$
\begin{aligned}
\frac{\partial}{\partial t^{\prime}} \int_{-\infty}^{\infty} d r \int_{-\infty}^{\infty} e^{-x^{\prime}} p d x^{\prime} & \\
& =-r_{0} \int_{-\infty}^{\infty} d r \int_{-\infty}^{\infty} e^{-x} \frac{\partial p}{\partial x^{\prime}} d x^{\prime}+\left[f\left(r_{0}\right) \frac{\partial}{\partial r_{0}}+\frac{1}{2} g^{2}\left(r_{0}\right) \frac{\partial^{2}}{\partial r_{0}^{2}}\right] \int_{-\infty}^{\infty} d r \int_{-\infty}^{\infty} e^{-x^{\prime}} p d x^{\prime}
\end{aligned}
$$

which from Eq. (A6) can be written as

$$
\begin{aligned}
\frac{\partial}{\partial t^{\prime}} \int_{-\infty}^{\infty} d r \int_{-\infty}^{\infty} e^{-x^{\prime}} p d x^{\prime} & \\
& =-r_{0} \int_{-\infty}^{\infty} d r \int_{-\infty}^{\infty} e^{-x^{\prime}} \frac{\partial p}{\partial x^{\prime}} d x^{\prime} \\
& +\left[f\left(r_{0}\right) \frac{\partial}{\partial r_{0}}+\frac{1}{2} g^{2}\left(r_{0}\right) \frac{\partial^{2}}{\partial r_{0}^{2}}\right] D\left(t^{\prime} \mid r_{0}\right)
\end{aligned}
$$

Let us now integrate by parts the integral term on the right hand side of Eq. (A7) and using again Eq. (A6) we get

$$
\int_{-\infty}^{\infty} d r \int_{-\infty}^{\infty} e^{-x^{\prime}} \frac{\partial p}{\partial x^{\prime}} d x^{\prime}=\int_{-\infty}^{\infty} d r \int_{-\infty}^{\infty} e^{-x^{\prime}} p d x^{\prime}=D\left(t^{\prime} \mid r_{0}\right)
$$

where we have taken into account the boundary condition [otherwise implicit in the definition of $D$ given in Eq. (A6)]

$$
\lim _{x \rightarrow \pm \infty}\left[e^{-x^{\prime}} p\left(x^{\prime}, r, t^{\prime} \mid r_{0}\right]=0\right.
$$

Substituting Eq. (A8) into Eq. (A7) and setting $t_{0}=0$ which implies $t^{\prime}=t$ [cf. Eq. (A3)] we obtain the Feynman-Kac equation

$$
\frac{\partial D}{\partial t}=-r_{0} D+f\left(r_{0}\right) \frac{\partial D}{\partial r_{0}}+\frac{1}{2} g^{2}\left(r_{0}\right) \frac{\partial^{2} D}{\partial r_{0}^{2}}
$$

with the initial condition [cf. Eqs. (A5) and (A6)]

$$
D\left(0 \mid r_{0}\right)=1
$$

In some applications as, for instance, those related to bond pricing (see Appendix B) it is convenient to consider $t_{0} \neq 0$ so that $t^{\prime}=t-t_{0} \neq t$. In these cases it is appropriate to denote $D=D\left(t \mid r_{0}, t_{0}\right)$ and the Feynman-Kac equation reads

$$
\frac{\partial D}{\partial t_{0}}=r_{0} D-f\left(r_{0}\right) \frac{\partial D}{\partial r_{0}}-\frac{1}{2} g^{2}\left(r_{0}\right) \frac{\partial^{2} D}{\partial r_{0}^{2}}
$$

with the final condition $D\left(t \mid r_{0}, t\right)=1$

\section{Appendix B. Pricing bonds. The term structure of interest rates}

In this appendix we ouline the theory of bond pricing which is closely connected to discounting. We mostly follow the short introduction presented in Masoliver (2018) and refer the interested reader to 
more exhaustive and specialized texts (as, for example, Brigo and Mercurio, 2006) for further information.

\section{Definitions}

As mentioned in Sect. II, a bond is an instrument that one purchases now and delivers a payment in the future. From a more technical point of view, we say that a (discount) bond is a default-free claim on a specified sum of money to be delivered at a given future date called maturity time. Such claims are bought and sold by investors. Let us denote by $B\left(t_{0}, t\right)$ the price at time $t_{0}$ of a discount bond maturing at time $t \geq t_{0}$, with unit maturity value $\mathrm{e}^{30}$

$$
B(t, t)=1
$$

Bonds are classified according to the time interval to maturity $\tau$ defined as

$$
\tau=t-t_{0}
$$

( $\tau \geq 0$ ). Thus, if $\tau=10$ years we talk about a 10 year bond that is traded initially at $t_{0}$ (for instance, today) with price $B\left(t_{0}, t_{0}+10\right)$ and which after 10 years has unit value. Similarly for a 3 month bond, 3 year bond, etc. The central question consists in knowing the backward evolution of the bond price, from unit maturity to the initial price $B\left(t_{0} \mid t\right)$ :

$$
\begin{aligned}
& t=t_{0} \leftarrow t=t_{0}+\tau \\
& B\left(t_{0}, t\right) \leftarrow \quad 1
\end{aligned}
$$

We define the instantaneous rate of return $r\left(t_{0}, t\right)$ (also called forward rate) as the relative time variation of the bond price [see Eq. (2)]

$$
r\left(t_{0}, t\right) \equiv \frac{1}{B\left(t_{0}, t\right)} \frac{d B\left(t_{0}, t\right)}{d t_{0}}
$$

or equivalently

$$
r\left(t_{0}, t\right)=\frac{d \ln B\left(t_{0}, t\right)}{d t_{0}}
$$

The knowledge of the forward rate $r\left(t_{0}, t\right)$ allows us to relate the initial price $B\left(t_{0}, t\right)$ and the maturing price $B(t, t)=1$. Indeed, taking into account this final condition on the bond price, the integration of (B2) directly leads to ${ }^{31}$

$$
B\left(t_{0}, t\right)=\exp \left\{-\int_{t_{0}}^{t} r\left(t_{0}, t^{\prime}\right) d t^{\prime}\right\}
$$

The comparison of Eq. (B3) with Eq. (9) shows that $B\left(t_{0}, t\right)$ is the equivalent of the discount function $\delta(t)$ while the forward rate $r\left(t_{0}, t\right)$ is the equivalent of the discount rate $r(t)$. However, in what follows, we will use the notation $r(t)$ for the so-called spot rate which we will define below.

Another quantity of interest is the yield to maturity $y\left(t_{0}, \tau\right)$ defined by

$$
y\left(t_{0}, \tau\right) \equiv-\frac{1}{\tau} \ln B\left(t_{0}, t_{0}+\tau\right)
$$

and from (B3) we see that

$$
y\left(t_{0}, \tau\right)=\frac{1}{\tau} \int_{t_{0}}^{t_{0}+\tau} r\left(t_{0}, t^{\prime}\right) d t^{\prime}
$$

\footnotetext{
${ }^{30}$ If the final maturity price is not 1 (say, $B(t \mid t)=\beta$ ) then the (initial) bond price would be $\beta B\left(t_{0}, t\right)$.

${ }^{31}$ Note that Eqs. (B3) and (11) are the same, although in this appendix we will use the notation $r\left(t_{0}, t\right)$ instead of $n\left(t_{0}, t\right)$ for the nominal (or forward) rate.
} 
That is to say, the yield is the time average of the forward rate over the maturity period $\tau$.

A final quantity is needed, the spot rate, which is defined as the limit of the yield when maturity tends to 0 ,

$$
r\left(t_{0}\right) \equiv \lim _{\tau \rightarrow 0} y\left(t_{o}, \tau\right)=\lim _{\tau \rightarrow 0}\left\{\frac{1}{\tau} \int_{t_{0}}^{t_{0}+\tau} r\left(t_{0}, t^{\prime}\right) d t^{\prime}\right\}
$$

Solving the indeterminacy by expanding the integral in powers of $\tau$, we see that the spot rate is given in terms of the forward rate by

$$
r\left(t_{0}\right)=r\left(t_{0}, t_{0}\right)
$$

In other words, the spot rate is the instantaneous forward rate.

Let us also observe that a loan of amount $M$ subscribed at time $t_{0}$ with an interest rate $r\left(t_{0}\right)$ (the spot rate) will, at time $t_{0}+d t_{0}$, increase in value to $M+d M$, where

$$
d M=r\left(t_{0}\right) M d t_{0}
$$

Indeed, at any time $t_{0}$, the value of the spot rate $r\left(t_{0}\right)$ is the instantaneous increase of the loan value, that is, $r\left(t_{0}\right)=d \ln M\left(t_{0}\right) / d t$ (compare with Eq. (B2)). ${ }^{32}$ However, subsequent values of the spot rate are not necessarily certain. We will see next the consequences of this fact on the time evolution of the bond price $B\left(t_{0}, t\right)$.

\section{Dynamics of the bond price}

Suppose the spot rate $r\left(t_{0}\right)$ is random. In such a case, and analogously to discounting, the usual assumption is that $r_{0}=r\left(t_{0}\right)$ is a Markovian random process with continuous trajectories; that is, a diffusion process obeying a stochastic differential equation of the form

$$
d r_{0}=f\left(r_{0}\right) d t_{0}+g\left(r_{0}\right) d W\left(t_{0}\right)
$$

Where $W\left(t_{0}\right)$ is the standard Wiener process. We have assumed that the drift and the noise intensity are independent of time (as is the case in most applications) thus the time dependence of these coefficients is implicit through $r_{0}=r\left(t_{0}\right)$. We know that this implies invariance under time translations and we can set $t_{0}=0$ when needed without loss of generality.

We will now follow Vasicek (1977) and obtain the time evolution of the bond price $B\left(t_{0}, t\right)$ at maturity $t>t_{0}$. To this end, let us first observe that the most natural hypothesis consists in assuming that the bond Price $B$ is a function of the initial spot rate $r\left(t_{0}\right)$, in addition to the obvious dependence on the time $t_{0}$ when the bond was issued. We thus write

$$
B=B\left[t_{0}, t \mid r\left(t_{0}\right)\right]
$$

In this way $B\left(t_{0}, t \mid r_{0}\right)$ represents the price of a bond issued at time $t_{0}$ and maturing at time $t$, given that the initial interest rate is $r_{0}=r\left(t_{0}\right)$.

The infinitesimal variation of the bond price is then defined by

$$
d B=B\left[t_{0}+d t_{0}, t \mid r\left(t_{0}+d t_{0}\right)\right]-B\left[t_{0}, t \mid r\left(t_{0}\right)\right]
$$

We expand in Tailor series up to second order

$$
\begin{aligned}
B\left[t_{0}+d t_{0}, t \mid r\right. & \left.\left(t_{0}+d t_{0}\right)\right] \\
& =B\left[t_{0}, t \mid r\left(t_{0}\right)\right]+\frac{\partial B}{\partial t_{0}} d t_{0}+\frac{\partial B}{\partial r_{0}} d r_{0}+\frac{1}{2}\left[\frac{\partial^{2} B}{\partial t_{0}^{2}} d t_{0}^{2}+\frac{\partial^{2} B}{\partial r_{0}^{2}} d r_{0}^{2}+\frac{\partial^{2} B}{\partial t_{0} \partial r_{0}} d t_{0} d r_{0}\right] \\
& +\cdots
\end{aligned}
$$

Hence

\footnotetext{
${ }^{32}$ Let us remark again the close similarities with discounting.
} 


$$
d B=\frac{\partial B}{\partial t_{0}} d t_{0}+\frac{\partial B}{\partial r_{0}} d r_{0}+\frac{1}{2}\left[\frac{\partial^{2} B}{\partial t_{0}^{2}} d t_{0}^{2}+\frac{\partial^{2} B}{\partial r_{0}^{2}} d r_{0}^{2}+\frac{\partial^{2} B}{\partial t_{0} \partial r_{0}} d t_{0} d r_{0}\right]
$$

Recalling the standard property of the Wiener noise that its infinitesimal variation is of order of $d t_{0}^{1 / 2}$ (Masoliver, 2018):

$$
d W\left(t_{0}\right)=O\left(d t_{0}^{\frac{1}{2}}\right)
$$

we have [cf. Eq. (B8)] $d r_{0}^{2}=g^{2}\left(r_{0}\right) d t_{0}+O\left(d t_{0}^{\frac{3}{2}}\right)$ and substituting this and Eq. (B8) into Eq. (B10) we finally obtain up to first order in $d t_{0}$ :

$$
d B=\left[\frac{\partial B}{\partial t_{0}}+f\left(r_{0}\right) \frac{\partial B}{\partial r_{0}}+\frac{1}{2} g^{2}\left(r_{0}\right) \frac{\partial^{2} B}{\partial r_{0}^{2}}\right] d t_{0}+g\left(r_{0}\right) \frac{\partial B}{\partial r_{0}} d W\left(t_{0}\right)
$$

Defining

$$
\mu\left(t_{0}, t \mid r_{0}\right) \equiv \frac{1}{B}\left[\frac{\partial B}{\partial t_{0}}+f\left(r_{0}\right) \frac{\partial B}{\partial r_{0}}+\frac{1}{2} g^{2}\left(r_{0}\right) \frac{\partial^{2} B}{\partial r_{0}^{2}}\right]
$$

and

$$
\sigma\left(t_{0}, t \mid r_{0}\right) \equiv-\frac{1}{B} g\left(r_{0}\right) \frac{\partial B}{\partial r_{0}}
$$

we see from (B11) that the bond price satisfies the stochastic differential equation

$$
\frac{d B}{B}=\mu\left(t_{0}, t \mid r_{0}\right) d t_{0}-\sigma\left(t_{0}, t \mid r_{0}\right) d W\left(t_{0}\right)
$$

showing that the bond price is a diffusion process as well.

Averaging Eq. (B14) and bearing in mind that $\mathbb{E}\left[d W\left(t_{0}\right)\right]=0$ we see that

$$
\mu=\left(t_{0}, t \mid r_{0}\right)=\mathbb{E}\left[\frac{1}{B} \frac{d B}{d t_{0}}\right]
$$

which proves that $\mu\left(t_{0}, t \mid r_{0}\right)$ is the average of the instantaneous rate of return [cf. Eq. (B1)] at time $t_{0}$ on a bond with maturing date $t$, given that the current spot rate is $r_{0}$. In an analogous way one can easily show that $\sigma^{2}\left(t_{0}, t \mid r_{0}\right)$ is the variance.

We therefore see from the above development that the bond price is a random quantity. The question now is: what is the price that an investor has to buy (or sell) a bond at time $t_{0}$ maturing at time $t=$ $t_{0}+\tau$ with the current spot rate $r_{0}$ ? One possible answer would be proceeding as in discounting and take the average over all possible realizations of the bond price. However, this procedure implies that the expected rate of return of a bond is invariant under risk variation -i.e., under changes of the variance $\sigma^{2}\left(t_{0} ; t \mid r_{0}\right)$ - a fact that investors always have in mind. We next present a procedure resulting in a deterministic bond price which takes into account the risk aversion of investors. ${ }^{33}$

\section{The market price of risk}

Consider an investor who, at time $t_{0}$, sells an amount worth $M_{1}$ of a bond maturing at time $t_{1}$. and at the same time buys an amount worth $M_{2}$ of another bond with a different maturing date $t_{2}$. The total worth of the portfolio thus constructed is $M=M_{2}-M_{1}$. Note that the quantities $M_{1}$ are multiples of the bond prices $B\left(t_{0} ; t_{i} \mid r_{0}\right)(i=1 ; 2)$ and, hence, obey the $\operatorname{SDE}(\mathrm{B} 14)$. That is to say,

\footnotetext{
${ }^{33}$ In practice this is true only to some extend because the theoretical procedure assumes that the market is driven by Gaussian white noise (i.e., the Wiener process) which is an idealized noise presenting -among other shortcomings- no fat tails, a key characteristic of real markets.
} 


$$
\frac{d M_{i}}{M_{i}}=\mu\left(t_{0}, t_{i} \mid r_{0}\right) d t_{0}+\sigma\left(t_{0}, t_{i} \mid r_{0}\right) d W\left(t_{0}\right)
$$

In consequence the infinitesimal variation $d M=d M_{2}-d M_{1}$ of the portfolio value changes over time according to

$$
\begin{aligned}
& d M=\left[\mu\left(t_{0}, t_{2} \mid r_{0}\right) M_{2}-\mu\left(t_{0}, t_{1} \mid r_{0}\right) M_{1}\right] d t_{0} \\
& +\left[\sigma\left(t_{0}, t_{2} \mid r_{0}\right) M_{2}-\sigma\left(t_{0}, t_{1} \mid r_{0}\right) \mathrm{M}_{1}\right] d W\left(t_{0}\right)
\end{aligned}
$$

Suppose we choose the amounts $M_{1}$ and $M_{2}$ such that

$$
M_{1}=\frac{M}{\sigma_{2}-\sigma_{1}} \sigma_{2}, \quad M_{1}=\frac{M}{\sigma_{2}-\sigma_{1}} \sigma_{1}
$$

where $M=M_{2}-M_{1}$ and $\sigma_{i}=\sigma\left(t_{0}, t_{i} \mid r_{0}\right)(i=1,2)$. Hence $M_{1}$ is proportional to $\sigma_{2}$ while $M_{2}$ is proportional to $\sigma_{1}$. With this choice we have

$$
\sigma_{2} M_{2}-\sigma_{1} M_{1}=\sigma_{2} \frac{\sigma_{1} M}{\sigma_{2}-\sigma_{1}}-\sigma_{1} \frac{\sigma_{2} M}{\sigma_{2}-\sigma_{1}}=0
$$

and the random term in Eq. (B15) vanishes. This renders the portfolio composed of such amounts of the two bonds instantaneously riskless:

$$
d M=\frac{M}{\sigma_{1}-\sigma_{2}}\left(\mu_{2} \sigma_{1}-\mu_{1} \sigma_{2}\right) d t_{0}
$$

where $\mu_{i}=\mu\left(t_{0}, t_{i} \mid r_{0}\right)$. The rate of return $r_{M}$ of this portfolio is

$$
r_{M} \equiv \frac{1}{M} \frac{d M}{d t_{0}}=\frac{\mu_{2} \sigma_{1}-\mu_{1} \sigma_{2}}{\sigma_{1}-\sigma_{2}}
$$

In order to avoid arbitrage opportunities -that is, making profits without taking any risk- the rate $r_{M}$ must be equal to the spot rate $r_{0}$. If not, the portfolio can be purchased by taking funds borrowed at the spot rate, or otherwise sold and the profits lent out to accomplish a riskless arbitrage (see Vasicek, 1977, for more details). Therefore, $r_{M}=r_{0}$, that is

$$
r_{0}=\frac{\mu_{2} \sigma_{1}-\mu_{1} \sigma_{2}}{\sigma_{1}-\sigma_{2}}
$$

Rearranging terms we get $\left(\mu_{1}-r_{0}\right) / \sigma_{1}=\left(\mu_{2}-r_{0}\right) / \sigma_{2}$, so that

$$
\frac{\mu\left(t_{0}, t_{1} \mid r_{0}\right)-r_{0}}{\sigma\left(t_{0}, t_{1} \mid r_{0}\right)}=\frac{\mu\left(t_{0}, t_{2} \mid r_{0}\right)-r_{0}}{\sigma\left(t_{0}, t_{2} \mid r_{0}\right)}
$$

This equation is valid for arbitrary maturities $t_{1}, t_{2} \ldots$, it then follows that the ratio $\left[\mu\left(t_{0}, t \mid r_{0}\right)-r_{0}\right] / \sigma\left(t_{0}, t \mid r_{0}\right)$ must be $t$ independent of the maturity time $t$.

Let us denote by $q\left(t_{0} \mid r_{0}\right)$ the common value of such a ratio for a bond of any maturity date, given that the current spot rate is $r_{0}$,

$$
q\left(t_{0} \mid r_{0}\right) \equiv \frac{\mu\left(t_{0}, t \mid r_{0}\right)-r_{0}}{\sigma\left(t_{0}, t \mid r_{0}\right)}, \quad\left(t \geq t_{0}\right)
$$

The quantity $q\left(t_{0} \mid r_{0}\right)$ is called the market price of risk, as it gives the variation of the expected rate of return on a bond (specified by the risk premium $\mu-r_{0}$ ) per an additional unit risk (specified by the standard deviation $\sigma$ ).

Note that if $q=0$ the spot rate $r_{0}=r\left(t_{0}\right)$ and the average rate of return $\mu$ coincide.

$$
\mu\left(t_{0}, t \mid r_{0}\right)=r\left(t_{0}\right)
$$

$\left(t=t_{0}+\tau\right)$ meaning that the expected instantaneous rates of return on bonds are the same for all maturities. 


\section{The term structure equation}

The above development on the market price of risk allows us to obtain a deterministic equation for the bond price $B=B\left(t_{0}, t \mid r_{0}\right)$. In effect, writing Eq. (B18) as

$$
\mu\left(t_{0}, t \mid r_{0}\right)-r_{0}=\sigma\left(t_{0}, t \mid r_{0}\right) q\left(t_{0} \mid r_{0}\right)
$$

and substituting $\mu$ and $\sigma$ by their definitions given in Eqs. (B12) and (B13), we have

$$
\frac{1}{B}\left[\frac{\partial B}{\partial t_{0}}+f\left(r_{0}\right) \frac{\partial B}{\partial r_{0}}+\frac{1}{2} g^{2}\left(r_{0}\right) \frac{\partial^{2} B}{\partial r_{0}^{2}}\right]-r_{0}=-q\left(t_{0} \mid r_{0}\right) \frac{1}{B} g\left(r_{0}\right) \frac{\partial B}{\partial r_{0}}
$$

which after rearranging terms yields

$$
\frac{\partial B}{\partial t_{0}}=r_{0} B-\left[f\left(r_{0}\right)+g\left(r_{0}\right) q\left(t_{0} \mid r_{0}\right)\right] \frac{\partial B}{\partial r_{0}}-\frac{1}{2} g^{2}\left(r_{0}\right) \frac{\partial B}{\partial r_{0}^{2}}
$$

This equation -called the term structure equation- is a partial differential equation for $B\left(t_{0}, t \mid r_{0}\right)$, once the random character of the spot rate process $r(t)$ (through $f$ and $g$ ) is known and the market price of risk $q\left(t_{0} \mid r_{0}\right)$ is specified. Bond prices are obtained after solving (B19) with the final condition

$$
B\left(t, t \mid r_{0}\right)=1
$$

Note that the term structure equation (B19) for the bond price is identical to the Feynman-Kac equation (19) for the discount as long as we make the following change of drift

$$
f\left(r_{0}\right) \rightarrow f\left(r_{0}\right)+g\left(r_{0}\right) q\left(t_{0} \mid r_{0}\right)
$$

On the other hand, as we have seen in Appendix A, the solution of the Feynman-Kac equation (19) for the discount $D\left(t \mid r_{0}\right)$ is written as the average [cf. Eq. (15)]

$$
D\left(t \mid r_{0}, t_{0}\right)=\int_{-\infty}^{\infty} d r \int_{-\infty}^{\infty} e^{-x} p\left(x, r, t \mid r_{0}, t_{0}\right) d x
$$

where $p\left(x, r, t, \mid r_{0}, t_{0}\right)$ is the probability density function of the bidimensional diffusion process $(x(t), r(t))$ defined by Eq. (16),

$$
d x=r d t, d r=f(r) d t+g(r) d W(t)
$$

Now the analogy between the term structure equation (B19) and the Feynman-Kac equation (19) suggests that we can write the bond price $B\left(t_{0}, t \mid r_{0}\right)$ as an average over the different realizations of the spot rate $r\left(t_{0}\right)$. However, this averaging procedure is taken using a modified PDF called the risk-free measure. Thus it can be proved in a more rigorous way that (Vasicek, 1977; Duffie, 2001)

$$
B\left(t_{0}, t \mid r_{0}\right)=\int_{-\infty}^{\infty} d r \int_{-\infty}^{\infty} e^{-x} p^{*}\left(x, r, t \mid r_{0}, t_{0}\right) d x
$$

where $p^{*}\left(x, r, t \mid r_{0}, t_{0}\right)$ is the risk-free measure which is the PDF of the bidimensional process $\left(x\left(t_{0}\right), r\left(t_{0}\right)\right)$ defined by the following pair of SDEs which include the market price of risk [see Eq. (B21)]:

$$
\begin{gathered}
d x=r d t \\
d r=[f(r)+g(r) q(t \mid r)] d t+g(r) d W(t)
\end{gathered}
$$

That is, $p^{*}$ is the solution to the FPE

$$
\frac{\partial p^{*}}{\partial t}=-r \frac{\partial p^{*}}{\partial x}-\frac{\partial}{\partial r}\left[[f(r)+g(r) q(t \mid r)] p^{*}\right]+\frac{1}{2} \frac{\partial^{2}}{\partial r^{2}}\left[g^{2}(r) p^{*}\right]
$$

with the final condition

$$
p^{*}\left(x, r, t_{0} \mid r_{0}, t_{0}\right)=\delta(x) \delta\left(r-r_{0}\right)
$$


Since, as we have shown in Appendix A, the Feynman-Kac approach to discounting is equivalent to the Fourier method described in the main text, we can apply the latter to obtain directly the bond price knowing only the risk neutral PDF, without having to solve the Feynman-Kac equation (B19) with condition (A5). Indeed, the characteristic function of the risk neutral density $p^{*}$ is the joint Fourier transform

$$
\bar{p}^{*}\left(w_{1}, w_{2}, t \mid r_{0}, t_{0}\right)=\int_{-\infty}^{\infty} e^{-i w_{2} r} d r \int_{-\infty}^{\infty} e^{-i w_{1} x} p^{*}\left(x, r, t \mid r_{0}, t_{0}\right) d x
$$

which after comparing whit Eq. (B22) yields

$$
B\left(t_{0}, t \mid r_{0}\right)=\bar{p}^{*}\left(w_{1}=-i, w_{2}=0, t \mid r_{0}, t_{0}\right)
$$

Finally, once we know the bond price, the yield to maturity $y\left(t_{0}, \tau \mid r_{0}\right)$ (also called the term structure of interest rate) is readily evaluated from Eq. (B4):

$$
y\left(t_{0}, \tau \mid r_{0}\right)=-\frac{1}{\tau} \ln B\left(t_{0}, t_{0}+\tau \mid r_{0}\right)
$$

The graphic representations of $y\left(t_{0}, \tau \mid r_{0}\right)$ as a function of $t_{0}$ and for different values of the maturity interval $\tau$ are called yield curves and are of prime importance for practitioners.

\section{REFERENCIAS BIBLIOGRÁFICAS}

ARROW, K. J., CROPPER, M. L., GOLLIER, C., GROOM, B., HEAL, G. M., NEWELL, R. G., NORDHAUS, W. D., PINDYCK, R. S., PIZER, W. A., PORTNEY, P. R., STERNER, T., TOL, R. S. J., WEITZMAN, M. L., 2013. Determining benefits and costs for future generations. Science 341, 349-350.

BRIGO, D., MERCURIO, F., 2006. Interest Rate Models- Theory and Practice. Springer-Verlag, Berlin and New York.

COX, J. C., INGERSOLL, J. E., ROSS, S. A., 1981. A re-examination of the traditional hypothesis about the term structure of interest rates. Journal of Finance 36, 769-799.

COX, J. C., INGERSOLL, J. E., ROSS, S. A., 1985. A theory of the term structure of interest rates. Econometrica $53,385-407$.

DASGUPTA, P., 2004. Human Well-Being and the Natural Environment. Oxford University Press, Oxford.

DASGUPTA, P., 2006. Comments on the Stern Review's Economics of Climate Change. Cambridge University Press, Cambridge.

DOTHAN, L. U., 1978. On the term structure of interest rates. Journal of Financial Economics 6, 59-69.

DUFFIE, D., 2001. Dynamic asset pricing theory. Princeton University Press, Princeton.

FARMER, J. D., GEANAKOPLOS, J., 2009. Hyperbolic discount is rational: Valuing the far future with uncertain discount rates. Working paper, SSRN.

FARMER, J. D., GEANAKOPLOS, J., MASOLIVER, J., MONTERO, M., PERELLO, J., 2014. Discounting the distant future. Cowles Foundation Discussion Paper No. 1951 (Yale University).Available at SSRN: http://ssrn.com/Abstract=1448811.

FARMER, J. D., GEANAKOPLOS, J., MASOLIVER, J., MONTERO, M., PERELLO, J., 2015. Value of the future: Discounting in random environments. Physical Review E 91, 052816.

FARMER, J. D., GEANAKOPLOS, J., MASOLIVER, J., MONTERO, M., PERELLO, J., RICHIARDI, M. G., 2019. Discounting the distant future: What do historical bond prices imply about the long terms discount rate? (in preparation).

FELLER, W., 1951. Two singular diffusion processes. Annals of Mathematics 54, 173-182.

GARDINER, C., 1986. Handbook os Stochastic Methods. Springer-Verlag, Berlin.

GEANAKOPLOS, J., SUDDERTH, W., ZEITOUINI, O., 2014. Asymptotic behavior of a stochastic discount rate. Indian Journal of Statistics 76-A, 150-157.

GIGLIO, S., MAGGIORI, M., STROEBEL, J., 2015. Very long-run discount rates. Quarterly Journal of Economics $130,1$.

GILLES, C., LEROY, S. F., 1986. A note on the local expectation hypothesis. Journal of Finance 41, 975-979.

HEAL, G. M., MILNER, A., 2014. Agreeing to disagree on climate policy. Proceedings National Academy of Sciences, USA 111, 3695.

MASOLIVER, J., 2018. Random Processes, First-passage and Escape. World Scientific, Singapore.

MASOLIVER, J., PERELLÓ, J., 2012. First-passage and escape in the feller process. Phy. Rev. E 86, 041116.

MENDELSOHN, R. O., 2006. A critique of the stern report. Regulation 29, 42-46.

NEWELL, R., PIZER, N., 2003. Discounting the distant future: How much do uncertain rates increase valuations? Journal Environmental Economy and Management 46, 52-71.

NORDHAUS, W. D., 2007a. Critical assumptions in the stern review on climate change. Science 317, $201-202$.

NORDHAUS, W. D., 2007b. The stern review on the economics of climate change. Journal Economics Literature 45, 687-702. 
NORDHAUS, W. D., 2008. A Question of Balance. Yale University Press, New Haven.

PERELLÓ, J., MONTERO, M., MASOLIVER, J., FARMER, J. D., GEANAKOPLOS, J., 2019. Different economic scenarios increase the urgency to combat global warming (in preparation).

PIAZZESI, M., 2009. A_ne term structure models. In: Sahala, Y. A., Hansen, L. P. (Eds.), The handbook of_nancial econometrics. Elsevier, pp. 691-766.

PITT, H. R., 1958. Tauberian Theorems. Oxford University Press, Oxford.

RAMSEY, F. P., 1928. A mathematical theory of savings. Economic Journal 38, 543-559.

SAMUELSON, P., 1937. A note on measurement of utility. Review of Economic Studies 4, 155.

STERN, N., 2006. The Economics of Climate Change: The Stern Review. Cambridge University Press, Cambridge.

STERN, N., 2014a. Ethics, equity and the economics of climate change. paper 1: Science and philosophy. Economics and Philosophy 30, 397.

STERN, N., 2014b. Ethics, equity and the economics of climate change. paper 2: Economics and politics. Economics and Philosophy 30, 445.

VASICEK, O., 1977. An equilibrium characterization of the term structure. Journal of Financial Economics 5, 177188.

WEITZMAN, M. L., 2007. A review on the stern review on the economics of climate change. Journal of Economics Literature 45, 703-724. 